\title{
IMPLANTAÇÃO DOS PROCEDIMENTOS OPERACIONAIS PADRONIZADOS (POPs) DE HIGIENIZAÇÃO E DESINFECÇÃO DOS EQUIPAMENTOS E UTENSÍLIOS EM UMA UNIDADE DE ALIMENTAÇÃO E NUTRIÇÃO HOSPITALAR.
}

\author{
Caroline das Neves Mendes Nunes ${ }^{1}$ \\ Flavia Queiroga Aranha ${ }^{2}$ \\ Daniela Salate Biagioni Vulcano ${ }^{3}$
}

\begin{abstract}
Resumo
Em Unidades de Alimentação e Nutrição hospitalar (UAN), um surto de toxi-infecção alimentar pode trazer consequências desastrosas e agregar riscos de morte aos pacientes. Desta forma, a capacitação dos manipuladores de alimentos é fundamental para a garantia da qualidade das refeições produzidas. O objetivo do presente estudo foi implantar os POPs referentes à higienização e desinfecção dos equipamentos e utensílios, através de um treinamento contendo figuras ilustrativas e questões cotidianas sobre o tema; e avaliar a prática diária das atividades de higienização e desinfecção, antes e após a intervenção com os colaboradores da UAN. Foi elaborado e aplicado um roteiro de inspeção das boas práticas na higienização dos equipamentos e utensílios em dois momentos distintos, antes e depois da intervenção com os manipuladores de alimentos. Os resultados demonstraram uma relevante melhora na situação desta unidade quanto à prática, frequência e cumprimento das etapas referentes à higienização e desinfecção dos equipamentos e utensílios. Conclui-se que a implantação dos POPs de higienização e desinfecção foi efetivada com sucesso, e que a capacitação dos funcionários com treinamento dinâmico e interativo permite aos colaboradores um maior entendimento sobre a importância das práticas de higiene na rotina diária da UAN.
\end{abstract}

Palavras-chave: treinamento; manipuladores de alimentos; procedimento operacional padronizado.

\section{Introdução}

$\mathrm{Na}$ segunda metade do século XX, a sociedade brasileira passou por um intenso processo de transformação devido à revolução industrial. Dentre as mudanças, destacam-se os novos hábitos sociais e transformações no padrão de consumo alimentar. O hábito de "comer fora" tornou-se simultaneamente uma atividade social e uma necessidade imposta pelo modelo de força do trabalho em que a mulher passou a ter papel relevante.

Neste contexto gerou-se um grande aumento e desenvolvimento de estabelecimentos que produzem alimentos (ARAÚJO; CARDOSO, 2002). E as Unidades de Alimentação e

\footnotetext{
${ }^{1}$ Graduanda em Nutrição - IBB/UNESP, Botucatu - SP.

${ }^{2}$ Professora Assistente Doutora do Curso de Nutrição, Instituto de Biociências - Universidade Estadual Paulista "Júlio de Mesquita Filho" - UNESP - Botucatu.

${ }^{3}$ Nutricionista Técnica de Saúde do Núcleo de Nutrição e Dietética do Hospital das Clínicas da Faculdade de Medicina de Botucatu - SP.
} 
Nutrição (UANs) consolidaram-se como importantes setores dentro das empresas onde estão estabelecidas. Tais estabelecimentos incluem unidades de produção de porte e tipos de organização diferentes entre si, como restaurantes comerciais, restaurantes de hotéis, serviços de motéis, coffee shops, buffets, lanchonetes, cozinhas industriais, fast food, catering e cozinhas hospitalares (PAYNE-PALACIO, 1994).

Em se tratando de hospitais, onde o fornecimento de alimentos destina-se ao preparo de dietas especializadas que visam à recuperação e tratamento dos pacientes, dentre os objetivos das UANs verifica-se como prioridade o fornecimento de alimentação adequada, balanceada e segura. Nestes estabelecimentos, uma vez que os alimentos são direcionados a pessoas enfermas cuja imunidade pode estar debilitada, a responsabilidade com a inocuidade e segurança dos alimentos é maior ainda, podendo um surto de toxi-infecção alimentar em ambiente hospitalar trazer consequências desastrosas e agregar riscos de morte aos pacientes (NETO, 2006).

Segundo o comitê da World Health Organization/Food and Agriculture Organization WHO/FAO (WHO, 2006), as Doenças Transmitidas por Alimentos (DTAs) são os maiores problemas de saúde no mundo contemporâneo. No Brasil, estima-se que os estabelecimentos que produzem alimentos sejam responsáveis por mais de $50 \%$ dos surtos de toxi-infecções alimentares de origem bacteriana (BENEVIDES; LOVATTI, 2004).

Os surtos de toxi-infecções alimentares são causados principalmente pelos manipuladores de alimentos, pois são considerados os principais veiculadores de microorganismos patogênicos, quando procedem de técnicas incorretas durante a preparação dos alimentos. Neste contexto, relatam à baixa deficiência qualitativa e quantitativa desses colaboradores que contribui para as DTAs, pois este despreparo é refletido na higiene pessoal e nas condições de higienização do estabelecimento (GÓES et al., 2001; FAÇANHA et al., 2003).

Alguns autores sugerem que muitos casos de DTAs poderiam ser impedidos, se medidas preventivas fossem utilizadas em toda a cadeia produtiva. Entre elas, a implementação de ações voltadas para o controle de qualidade dos alimentos produzidos e a capacitação aos manipuladores de alimentos são fundamentais para os estabelecimentos, como o Serviço de Alimentação (SA) comercial e industrial e a UAN hospitalar, desempenham o propósito de proteger a saúde dos indivíduos, através da garantia de qualidade dos alimentos (REDMOND; GRIFFITH, 2003).

Diante do exposto, este trabalho tem o objetivo de implantar os POPs referentes à higienização e desinfecção dos equipamentos e utensílios, através de uma aula expositiva 
elaborada com recursos visuais para os manipuladores de alimentos; e avaliar a prática diária das atividades de higienização e desinfecção, antes e após esta intervenção com os colaboradores de uma UAN hospitalar localizada no interior de São Paulo.

\section{Métodos}

Primeiramente, foram avaliados os POPs sobre higienização e desinfecção dos equipamentos existentes na unidade, e elaborado aqueles que faltavam referentes aos utensílios. Estes documentos contêm as etapas referentes aos processos de higienização ou limpeza concorrente, nos quais todos os equipamentos e utensílios devem ser higienizados com esponja, detergente e álcool 70\%; e os de desinfecção ou limpeza terminal, no qual além da higienização comum, os utensílios e equipamentos deveriam ser colocados de molho em solução de hipoclorito a $1 \%$ por 15 minutos.

Em seguida, foi desenvolvido um roteiro de inspeção (em anexo) das boas práticas na higienização dos equipamentos e utensílios no serviço de alimentação, que abordava a presença ou ausência da higienização e desinfecção de cada equipamento e utensílio presente na unidade, assim como, se era realizada na frequência correta e se todas as etapas dos procedimentos de limpeza contidos nos POPs foram seguidas. Este roteiro permite a classificação da UAN conforme o cumprimento das atividades referentes à higienização dos equipamentos e utensílios, em ótimo, com atendimento dos itens acima de 75\%; em regular, de 50 a $75 \%$ de atendimento dos itens; e em irregular com menos de $50 \%$ de atendimento dos itens. Também foi criado um cronograma (em anexo) demonstrando todos os equipamentos e utensílios que deveriam ser higienizados diariamente, semanalmente e quinzenalmente.

Foi aplicado o roteiro de inspeção das boas práticas na higienização e desinfecção dos equipamentos e utensílios para quantificar e identificar os procedimentos de higienização que estavam sendo realizados, sem nenhuma intervenção com os manipuladores de alimentos da unidade. Após a análise dos resultados, foi produzido um treinamento para a capacitação dos funcionários no formato de apresentação do Microsoft Power Point ${ }^{\circledR}$ com os assuntos: Boas Práticas de Fabricação (BPF) no serviço de alimentação, e procedimentos de higienização e desinfecção dos equipamentos e utensílios.

O material de apoio utilizado para montar este treinamento foi à cartilha de boas práticas para serviços de alimentação formulada pela Agência de Vigilância Sanitária (ANVISA) de acordo com a resolução RDC n 216/2004, e os POPs referentes aos processos de limpeza dos equipamentos e utensílios da unidade. O treinamento foi aplicado em dois dias diferentes da mesma semana com o intuito de abordar todos os funcionários da UAN, ele era 
constituído por gravuras e imagens para aumentar a concentração dos participantes e por questões simples que permitiam a interação dos manipuladores de alimentos com a autora.

\section{Boas Práticas de Fabricação e Higienização e desinfecção dos equipamentos e utensílios}

\section{O que são as BPF?}

O que são as DTAs?

\section{O que são micróbios?}

Onde os micróbios podem ser encontrados?

Quando ocorre a contaminação do alimento?

É possível saber se o alimento está contaminado?

\section{Como evitar a contaminação dos alimentos?}

Temperatura ideal para conservação dos alimentos;

\section{Lavagem correta das mãos;}

Higienização adequada dos equipamentos e utensílios;

Etapas da limpeza concorrente ou diária dos equipamentos e utensílios;

Etapas da limpeza terminal ou semanal dos equipamentos e utensílios;

\section{Precauções no processo de higienização;}

Cuidados na diluição do hipoclorito de sódio.

Figura 1. Assuntos Abordados no Treinamento com os Manipuladores de Alimentos.

Em seguida, o cronograma sobre os processos de higienização e desinfecção foi colado em um cartaz contendo frases de incentivo aos colaboradores e afixado em um local de grande visualização pelos mesmos.

Por fim, uma semana após realizar o treinamento com os manipuladores de alimentos, foi novamente aplicado o roteiro de inspeção das boas práticas na higienização e desinfecção dos equipamentos e utensílios, a fim de quantificar e identificar se os procedimentos de higienização estavam sendo cumpridos, na frequência adequada e se todas as etapas necessárias foram atendidas; após a intervenção com os manipuladores de alimentos da unidade.

\section{Resultados e Discussão}

Os resultados obtidos na primeira aplicação do roteiro de inspeção das boas práticas na higienização dos equipamentos e utensílios classificam a unidade avaliada como irregular, pois esta apresentou somente $23 \%$ dos itens atendidos referentes à prática, a frequência e ao seguimento dos métodos adequados de higienização e desinfecção dos equipamentos e 
utensílios, como demonstrados na Figura 2. Sendo que destas atividades realizadas nenhuma delas seguiam os procedimentos preconizados pelos POPs, ou seja, os manipuladores de alimentos não realizavam os processos de higiene corretamente, de modo a garantir que os equipamentos e os utensílios estavam totalmente livres de sujeiras e contaminantes.

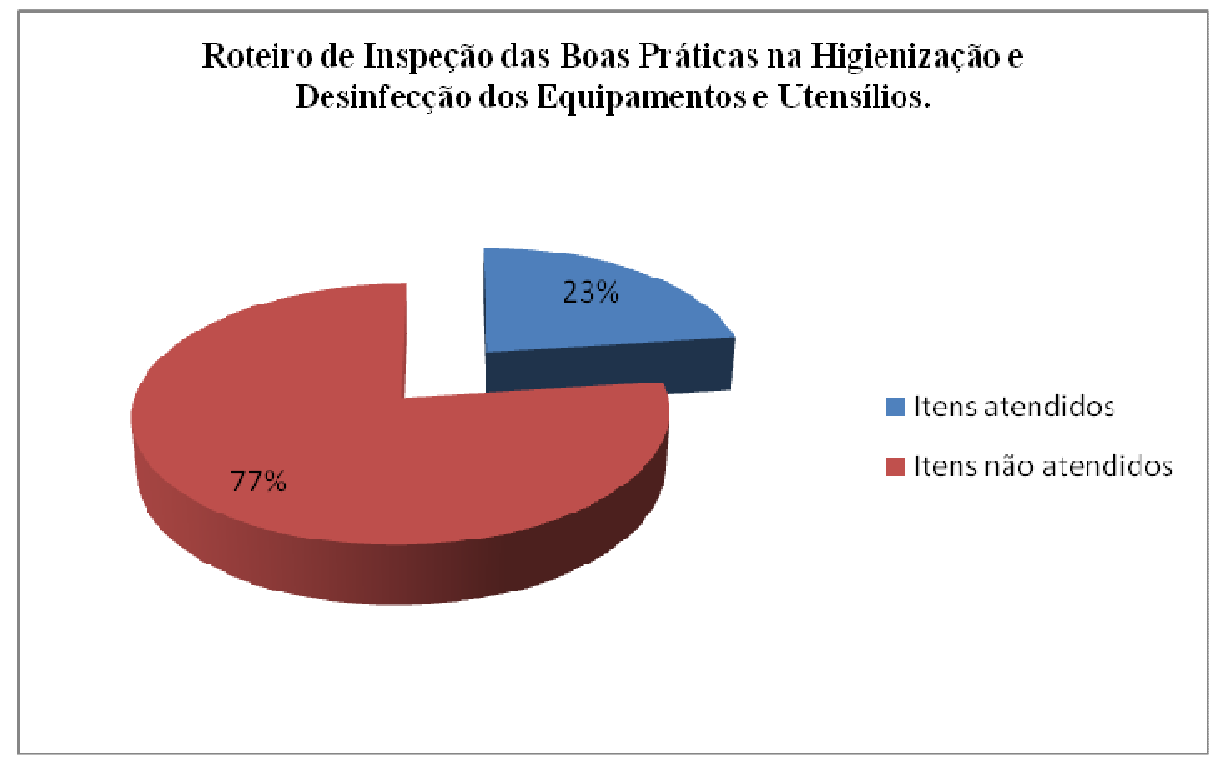

Figura 2. Classificação da UAN, segundo o percentual de atendimento dos itens imprescindíveis antes do treinamento.

Dentre as práticas de higienização e desinfecção não realizadas, é possível destacar: a higienização das caixas de polietileno; a higienização da máquina extratora de suco; a higienização do estoque de descartáveis; a desinfecção dos carros de distribuição; a desinfecção das caixas de polietileno; a desinfecção dos galões e garrafas térmicas; a desinfecção da esteira de porcionamento; a desinfecção dos carros térmicos; a desinfecção da geladeira e refrigeradores; e a desinfecção dos utensílios diversos.

Neste primeiro momento, é possível notar também que a higienização ou limpeza concorrente estava presente em $70 \%$ dos equipamentos e utensílios, enquanto a desinfecção ou limpeza terminal, não foi verificada em nenhuma prática avaliada.

Foi realizado o treinamento sobre os processos de higienização e desinfecção com 40 minutos de duração e contou com a presença de todos os funcionários e das nutricionistas responsáveis pela UAN. Esse envolvimento de toda empresa em programas de treinamento é fundamental para a eficiência da aplicação de ferramentas da qualidade (FIGUEIREDO; COSTA NETO, 2001). Durante toda a apresentação, os manipuladores de alimentos ficaram atentos com os assuntos, levantaram muitas questões importantes relacionadas ao tema, e 
demonstraram alcançar o entendimento sobre a importância de se realizar as práticas de higiene e desinfecção de modo correto.

O treinamento é o processo educacional de curto prazo aplicado de maneira sistemática e organizada, através dos quais as pessoas aprendem conhecimentos, atitudes e habilidades em função de objetivos definidos. Que envolve transmissão de conhecimentos específicos relativos ao trabalho, atitudes frente a aspectos da organização, da tarefa e do ambiente, e desenvolvimento de habilidades (CHIAVENATO, 2000). Esta prática promove inúmeros benefícios para as empresas de alimentos como: aumento da produtividade; higiene no trabalho; redução da rotatividade de mão de obra; melhoria das técnicas de fabricação e elaboração dos alimentos como consequência diminuição dos desperdícios; harmonia no ambiente de trabalho; segurança no trabalho, redução do índice de desistência ou falta ao trabalho (SANTOS, 1999). Além de reduzir o número de casos de surtos alimentares, provocando uma queda nos gastos com saúde pública e como consequência uma melhor qualidade de vida da população (HEIDEMANN et al., 2009).

Assim que completou uma semana após o último treinamento com os manipuladores de alimentos, o roteiro de inspeção das boas práticas na higienização dos equipamentos e utensílios foi novamente aplicado. Os resultados obtidos classificam a UAN como ótima, pois esta apresentou $88 \%$ de atendimento dos itens avaliados referentes à prática, a frequência e ao seguimento dos métodos adequados de higienização e desinfecção dos equipamentos e utensílios, como demonstrados na Figura 3.

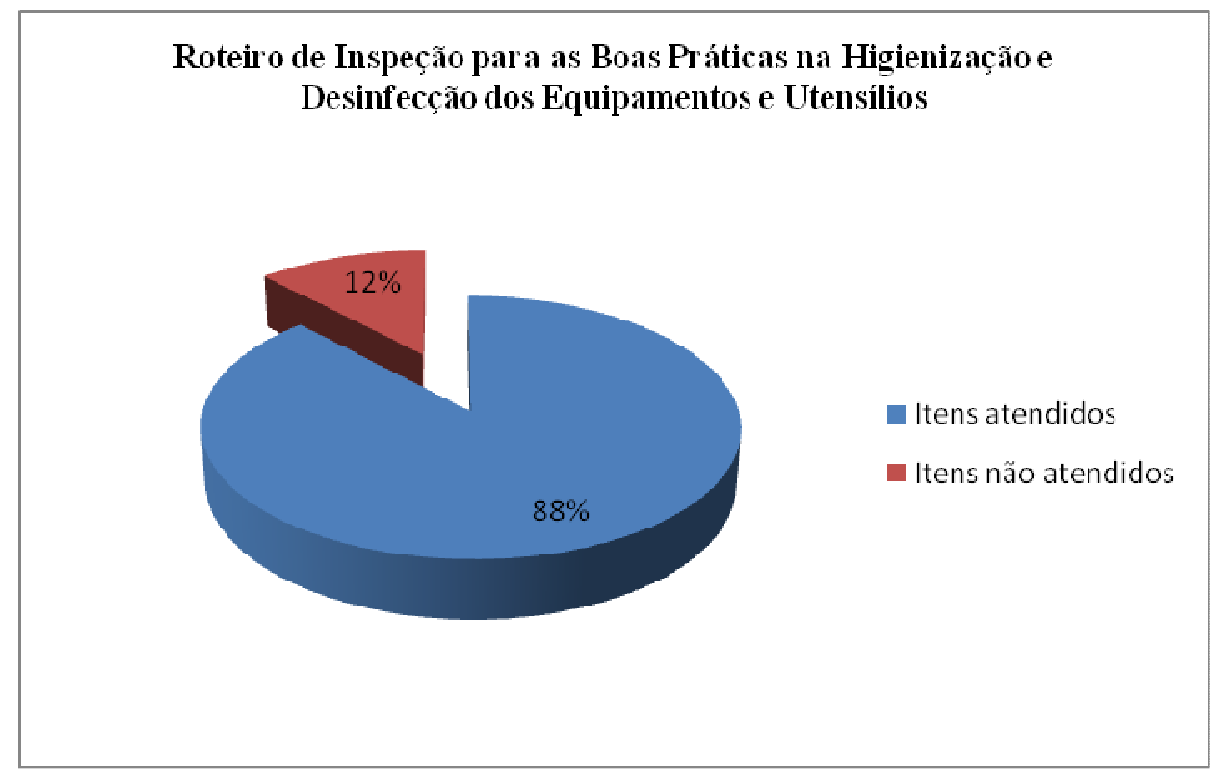

Figura 3. Classificação da UAN, segundo o percentual de atendimento dos itens imprescindíveis após o treinamento. 
Dentre as atividades realizadas apenas $9 \%$ delas não seguiam os procedimentos preconizados pelos POPs, pois os funcionários apresentavam dúvidas se os equipamentos correspondentes podiam danificados se higienizados com álcool $70 \%$ e hipoclorito de sódio. E das práticas de higienização e desinfecção dos equipamentos e utensílios avaliados no roteiro de inspeção, a única que não foi realizada pelos manipuladores de alimentos, foi a higienização e desinfecção do estoque de descartáveis, pois os colaboradores apresentavam-se relutantes em aceitar que a limpeza desta área era de responsabilidade deles.

Desta forma, com exceção do item comentado acima, a higienização ou limpeza concorrente, assim como a desinfecção ou limpeza terminal dos equipamentos e utensílios estavam presentes em todos os itens avaliados, demonstrando assim a evolução das práticas referentes aos processos de higienização e desinfecção realizados na unidade após o treinamento com os manipuladores de alimentos.

\section{Conclusão}

Diante dos resultados obtidos com a aplicação do roteiro de inspeção aplicados em dois momentos diferentes, é possível notar que a implantação de POPs referentes à higienização e desinfecção dos equipamentos e utensílios foi efetivada com sucesso. E que a capacitação dos colaboradores com treinamento em forma de apresentações e conversas dinâmicas e interativas produz excelentes resultados na rotina diária das tarefas que devem ser executas em uma UAN. Uma vez que a finalidade do treinamento de manipuladores é possibilitar-lhes princípios teóricos e práticos a fim de capacitá-los para executar atividades na área de alimentos. Sendo a forma mais recomendável e eficaz para se transmitir conhecimento e promover mudanças de conduta. Somente através desses programas é possível conseguir a produção de alimentos mais seguros e inócuos.

\section{Referências}

ANDREOTTI, A.; BALERONI, F.H; PAROSCHI, V.H.B; PANZA, S.G.A. Importância do treinamento para manipuladores de alimentos em relação a higiene pessoal. Revista de Iniciação Científica Cesumar, v. 5, n.1, p.29-33. Jan/jun., 2003. BRASIL.

ARAÚJO, W. M. C; CARDOSO, L. Qualidade dos Alimentos Comercializados no Distrito Federal no Período de1997-2001 [dissertação]. Brasília: Universidade deBrasília; 2002. 
BENEVIDES, C. M.; LOVATTI, R. C. C. Segurança Alimentar em Estabelecimentos Processadores de Alimentos. Higiene Alimentar, São Paulo. v. 18, n. 125, p. 24-27, out. 2004.

BRASIL. Agência Nacional de Vigilância Sanitária. Cartilha sobre as Boas Práticas para os Serviços de Alimentação. Resolução RDC n 216 , de 15 de setembro de 2004. Brasília, $3^{a}$ edição.

BRASIL. Agência Nacional de Vigilância Sanitária. Resolução RDC no 216, de 15 de setembro de 2004. Diário Oficial da República Federativa do Brasil, Poder Executivo, Brasília, DF, 16 set. 2004. Dispõe sobre regulamento técnico de boas práticas para serviços de alimentação.

CHIAVENATO, I. Gestão de pessoas. São Paulo: Campos, 2004.

FAÇANHA, S. H. F. et al. Treinamento para Manipuladores de Alimentos, em Escolas da Rede Municiapal de Ensino, da Sede e Distritos do Município de Meruoca, Ceará: Relato de Experiência. Higiene Alimentar, São Paulo, v. 17, n. 106, p. 30-39, 2003.

FIGUEIREDO, V. F.; COSTA NETO, P. L. O. Implantação de HACCP na indústria de Alimentos. Rev. Gestão \& Produção, v.8, n.1, p.100-111, abr. 2001.

GÓES, J. A. W. et al. Capacitação dos Manipuladores de Alimentos e a Qualidade da Alimentação Servida. Higiene Alimentar, São Paulo, v. 15, n. 82, p. 20-22, mar. 2001.

HEIDEMANN, R.; TRAEBERT, J. ; LACERDA, J. T. Nível de Conhecimento dos trabalhadores de indústrias de produtos suínos sobre a manipulação higiênica dos alimentos. Revista Higiene Alimentar, v. 23, n. 174/175, p.47-51, 2009.

NETO, M. S. Diagnóstico Situacional da Utilização das Ferramentas de Segurança na Produção de Alimentos nas Cozinhas das Unidades de Alimentação e Nutrição dos Hospitais de Brasília - DF. Dissertação (Mestrado), Universidade de Brasília, Distrito Federal, 2006.

PAYNE-PALACIO, J. West'sandWood'sIntroductiontofoodservice. New York: MacMillan; 1994.

REDMOND, E. C; GRIFFITH, C. J. ConsumerFoodHandling in theHouse: a ReviewofFoodSafetyStudies. J Food Prot., v. 66, n. 1, p. 130-161, 2003.

SANTOS, S. G. F. Treinando manipuladores de alimentos. São Paulo: Livraria Varela Ltda., 1999. 122p. 


\title{
IMPLEMENTATION OF STANDARD OPERATING PROCEDURES (SOPS) FOR SANITATION AND DISINFECTION OF EQUIPMENT AND UTENSILS OF A HOSPITAL UNIT OF FOOD AND NUTRITION (UFN)
}

\begin{abstract}
In a hospital UFNs, an outbreak of food poisoning can have disastrous consequences and aggregate risk of death for patients. Thus, the training of food handlers is critical to ensuring the quality of the food that is produced. The aim of this study was to implement the SOPs related to sanitation and disinfection of equipment and utensils, by means of a training, containing illustrative figures and everyday issues on the subject; and evaluate the daily practice of sanitation and disinfection activities before and after the intervention with employees of UFN. We developed and implemented a guidefor inspection of best practices in sanitation of equipment and utensils at two different times, before and after the intervention with the food handlers. The results showed a significant improvement in the situation of this unit in terms of practice, frequency and fulfillment of stages related to sanitation and disinfection of equipment and utensils. We concluded that the implementation of SOPs for sanitation and disinfection was carried out successfully, and that empowering employees with dynamic and interactive training allows them a greater understanding of the importance of hygiene practices in the daily routine of UFN.
\end{abstract}

Keywords: training; food handlers; standard operational procedure.

\section{ANEXOS}

I - Roteiro de Inspeção das Boas Práticas na Higienização de Utensílios e Equipamentos do Serviço de Alimentação

O roteiro de inspeção foi elaborado para avaliar se as práticas de higienização dos equipamentos e utensílios estão sendo cumpridas corretamente, seguindo todas as etapas do processo e frequência de execução das atividades conforme o recomendo pelos Procedimentos Operacionais Padrão (POP's) do serviço de alimentação.

\section{Legenda:}

$\mathbf{S}=\operatorname{Sim}=$ o estabelecimento inspecionado atende todos os quesitos do item de avaliação.

$\mathbf{N}=$ Não = o estabelecimento inspecionado não atende a um ou mais quesitos do item de avaliação.

NO $=$ Não observado $=$ o item de avaliação não pode ser observado durante a inspeção.

1. Higienização das caixas de polietileno. 
A higienização das caixas de polietileno é realizada diariamente?

$$
\mathbf{S}(\text { ) N ( ) NO ( ) }
$$

A higienização das caixas de polietileno segue todas as etapas preconizadas pelo POP?

$$
\mathbf{S}(\text { ) } \mathbf{N}(\text { ) NO ( ) }
$$

2. Higienização da caldeira de leite.

A higienização da caldeira de leite é realizada diariamente?

$$
\mathbf{S}(\text { ) } \mathbf{N}(\text { ) NO ( ) }
$$

A higienização da caldeira de leite segue todas as etapas preconizadas pelo POP?

$$
\mathbf{S}(\text { ) } \mathbf{N}(\text { ) NO ( ) }
$$

3. Higienização dos carros de distribuição.

A higienização dos carros de distribuição é realizada diariamente?

$$
\mathbf{S}(\text { ) } \mathbf{N}(\text { ) NO ( ) }
$$

A higienização dos carros de distribuição segue todas as etapas preconizadas pelo POP?

$$
\mathbf{S}(\text { ) } \mathbf{N}(\text { ) NO ( ) }
$$

4. Higienização dos galões e garrafas térmicas.

A higienização dos galões e garrafas térmicas é realizada diariamente?

$$
\mathbf{S}(\text { ) } \mathbf{N}(\text { ) NO ( ) }
$$

A higienização dos galões e garrafas térmicas segue todas as etapas preconizadas pelo POP?

$$
\mathbf{S}(\text { ) } \mathbf{N}(\text { ) NO ( ) }
$$

5. Higienização da máquina extratora de suco.

A higienização da máquina extratora de suco é realizada diariamente?

$$
\mathbf{S}(\text { ) } \mathbf{N}(\text { ) NO ( ) }
$$

A higienização da máquina extratora de suco segue todas as etapas preconizadas pelo POP?

$$
\mathbf{S}(\text { ) } \mathbf{N}(\text { ) NO ( ) }
$$

6. Higienização do liquidificador.

A higienização do liquidificador é realizada diariamente elou sempre que utilizado?

$$
\mathbf{S}(\text { ) } \mathbf{N}(\text { ) NO ( ) }
$$

A higienização do liquidificador segue todas as etapas preconizadas pelo POP?

$$
\mathbf{S}(\text { ) } \mathbf{N}() \mathbf{N O}(\text { ) }
$$


7. Higienização dos carros térmicos.

A higienização dos carros térmicos é realizada diariamente?

$$
\mathbf{S}(\text { ) N ( ) NO( ) }
$$

A higienização dos carros térmicos segue todas as etapas preconizadas pelo POP?

$$
\mathbf{S}(\text { ) } \mathbf{N}(\text { ) NO ( ) }
$$

8. Higienização da esteira de porcionamento.

A higienização da esteira de porcionamento é realizada diariamente?

$$
\mathbf{S}(\text { ) } \mathbf{N}(\text { ) NO ( ) }
$$

A higienização da esteira de porcionamento segue todas as etapas preconizadas pelo POP?

$$
\mathbf{S}(\text { ) N ( ) NO( ) }
$$

9. Higienização dos utensílios diversos.

A higienização dos utensílios diversos é realizada diariamente elou sempre que utilizado?

$$
\mathbf{S}(\text { ) } \mathbf{N}(\text { ) NO ( ) }
$$

A higienização dos utensílios diversos segue todas as etapas preconizadas pelo POP?

$$
\mathbf{S}(\text { ) } \mathbf{N}(\text { ) NO ( ) }
$$

10. Higienização do estoque de descartáveis.

A higienização do estoque de descartáveis é realizada quinzenalmente?

$$
\mathbf{S}(\text { ) } \mathbf{N}(\text { ) NO ( ) }
$$

A higienização do estoque de descartáveis segue todas as etapas preconizadas pelo POP?

$$
\mathbf{S}(\text { ) } \mathbf{N}(\text { ) NO ( ) }
$$

11. Higienização e desinfecção dos carros de distribuição.

A higienização e desinfecção dos carros de distribuição são realizadas semanalmente?

$$
\mathbf{S}(\text { ) } \mathbf{N}(\text { ) NO ( ) }
$$

A higienização e desinfecção dos carros de distribuição seguem todas as etapas preconizadas pelo POP?

\section{$\mathbf{S}($ ) $\mathbf{N}($ ) NO( )}

12. Higienização e desinfecção das caixas de polietileno.

A higienização e desinfecção das caixas de polietileno são realizadas semanalmente?

$$
\mathbf{S}(\text { ) } \mathbf{N}(\text { ) NO ( ) }
$$


A higienização e desinfecção dos carros de distribuição seguem todas as etapas preconizadas pelo POP?

$$
\mathbf{S}(\text { ) } \mathbf{N}(\text { ) NO( ) }
$$

13. Higienização e desinfecção dos galões e garrafas térmicas.

A higienização e desinfecção dos galões e garrafas térmicas são realizadas semanalmente?

$$
\mathbf{S}(\text { ) } \mathbf{N}(\text { ) NO ( ) }
$$

A higienização e desinfecção dos galões e garrafas térmicas seguem todas as etapas preconizadas pelo $\mathrm{POP}$ ?

$$
\mathbf{S}(\text { ) } \mathbf{N}() \mathbf{N O}(\text { ) }
$$

14. Higienização e desinfecção da esteira de porcionamento.

A higienização e desinfecção da esteira de porcionamento são realizadas semanalmente?

$$
\mathbf{S}(\text { ) } \mathbf{N}(\text { ) NO ( ) }
$$

A higienização e desinfecção da esteira de porcionamento seguem todas as etapas preconizadas pelo $P O P$ ?

$$
\mathbf{S}(\text { ) } \mathbf{N}(\text { ) NO ( ) }
$$

15. Higienização e desinfecção dos carros térmicos.

A higienização e desinfecção dos carros térmicos são realizadas semanalmente?

$$
\mathbf{S}(\text { ) } \mathbf{N}(\text { ) NO ( ) }
$$

A higienização e desinfecção dos carros térmicos seguem todas as etapas preconizadas pelo $P O P ?$

$$
\mathbf{S}(\text { ) } \mathbf{N}(\text { ) NO ( ) }
$$

16. Higienização e desinfecção da geladeira e refrigeradores.

A higienização e desinfecção da geladeira e refrigeradores são realizadas semanalmente?

$$
\mathbf{S}(\text { ) } \mathbf{N}(\text { ) NO ( ) }
$$

A higienização e desinfecção da geladeira e refrigeradores seguem todas as etapas preconizadas pelo POP?

$$
\mathbf{S}(\text { ) } \mathbf{N}() \mathbf{N O}(\text { ) }
$$

17. Higienização e desinfecção dos utensílios diversos.

A higienização e desinfecção dos utensílios diversos são realizadas semanalmente?

$$
\mathbf{S}(\text { ) } \mathbf{N}(\text { ) NO ( ) }
$$


A higienização e desinfecção dos utensílios diversos seguem todas as etapas preconizadas pelo POP?

\section{$\mathbf{S}($ ) $\mathbf{N}($ ) NO ( )}

18. Classificação do cumprimento das atividades referentes à higienização dos equipamentos e utensílios.

( ) Ótimo (acima de 75\% de atendimento dos itens).

( ) Regular (50 a 75\% de atendimento dos itens).

( ) Irregular (abaixo de 50\% de atendimento dos itens).

Em,

Nutricionista Responsável pelo NND 
II - Cronograma de Higienização e Desinfecção dos Equipamentos e Utensílios

$\checkmark$ Copeiros

\begin{tabular}{|c|c|c|c|c|c|c|}
\hline $\begin{array}{l}\text { Segunda- } \\
\text { Feira }\end{array}$ & Terça-Feira & $\begin{array}{c}\text { Quarta- } \\
\text { Feira }\end{array}$ & Quinta-Feira & Sexta-Feira & Sábado & Domingo \\
\hline $\begin{array}{l}\text { Higienizar as } \\
\text { caixas de } \\
\text { polietileno } \\
\text { (COPEIROS) }\end{array}$ & $\begin{array}{l}\text { Higienizar as } \\
\text { caixas de } \\
\text { polietileno } \\
\text { (COPEIROS) }\end{array}$ & $\begin{array}{l}\text { Higienizar as } \\
\text { caixas de } \\
\text { polietileno } \\
\text { (COPEIROS) }\end{array}$ & $\begin{array}{l}\text { Desinfetar as } \\
\text { caixas de } \\
\text { polietileno } \\
\text { (COPEIROS) }\end{array}$ & $\begin{array}{l}\text { Higienizar as } \\
\text { caixas de } \\
\text { polietileno } \\
\text { (COPEIROS) }\end{array}$ & $\begin{array}{l}\text { Higienizar as } \\
\text { caixas de } \\
\text { polietileno } \\
\text { (COPEIROS) }\end{array}$ & $\begin{array}{l}\text { Higienizar as } \\
\text { caixas de } \\
\text { polietileno } \\
\text { (COPEIROS) }\end{array}$ \\
\hline $\begin{array}{c}\text { Higienizar a } \\
\text { caldeira do } \\
\text { leite }\end{array}$ & $\begin{array}{c}\text { Higienizar a } \\
\text { caldeira do } \\
\text { leite }\end{array}$ & $\begin{array}{l}\text { Higienizar a } \\
\text { caldeira do } \\
\text { leite (OFT e } \\
\text { ORTO) }\end{array}$ & $\begin{array}{l}\text { Higienizar a } \\
\text { caldeira do } \\
\text { leite (OFT e } \\
\text { ORTO) }\end{array}$ & $\begin{array}{c}\text { Higienizar a } \\
\text { caldeira do } \\
\text { leite (OFT e } \\
\text { ORTO) }\end{array}$ & $\begin{array}{l}\text { Higienizar a } \\
\text { caldeira do } \\
\text { leite (OFT e } \\
\text { ORTO) }\end{array}$ & $\begin{array}{l}\text { Higienizar a } \\
\text { caldeira do } \\
\text { leite (OFT e } \\
\text { ORTO) }\end{array}$ \\
\hline $\begin{array}{l}\text { Higienizar de } \\
\text { carros de } \\
\text { distribuição } \\
\text { (COPEIROS) }\end{array}$ & $\begin{array}{c}\text { Desinfetar os } \\
\text { carros de } \\
\text { distribuição } \\
\text { (COPEIROS) }\end{array}$ & $\begin{array}{l}\text { Higienizar de } \\
\text { carros de } \\
\text { distribuição } \\
\text { (COPEIROS) }\end{array}$ & $\begin{array}{l}\text { Higienizar de } \\
\text { carros de } \\
\text { distribuição } \\
\text { (COPEIROS) }\end{array}$ & $\begin{array}{l}\text { Higienizar de } \\
\text { carros de } \\
\text { distribuição } \\
\text { (COPEIROS) }\end{array}$ & $\begin{array}{l}\text { Higienizar de } \\
\text { carros de } \\
\text { distribuição } \\
\text { (COPEIROS) }\end{array}$ & $\begin{array}{l}\text { Higienizar de } \\
\text { carros de } \\
\text { distribuição } \\
\text { (COPEIROS) }\end{array}$ \\
\hline \multirow[t]{2}{*}{$\begin{array}{l}\text { Desinfetar os } \\
\text { galões e } \\
\text { garrafas } \\
\text { térmicas } \\
\text { (COPEIROS) }\end{array}$} & $\begin{array}{c}\text { Higienizar os } \\
\text { galões e as } \\
\text { garrafas } \\
\text { térmicas } \\
\text { (COPEIROS) }\end{array}$ & $\begin{array}{l}\text { Higienizar os } \\
\text { galões e as } \\
\text { garrafas } \\
\text { térmicas } \\
\text { (COPEIROS) }\end{array}$ & $\begin{array}{l}\text { Higienizar os } \\
\text { galões e as } \\
\text { garrafas } \\
\text { térmicas } \\
\text { (COPEIROS) }\end{array}$ & $\begin{array}{l}\text { Higienizar os } \\
\text { galões e as } \\
\text { garrafas } \\
\text { térmicas } \\
\text { (COPEIROS) }\end{array}$ & $\begin{array}{l}\text { Higienizar os } \\
\text { galões e as } \\
\text { garrafas } \\
\text { térmicas } \\
\text { (COPEIROS) }\end{array}$ & $\begin{array}{l}\text { Higienizar os } \\
\text { galões e as } \\
\text { garrafas } \\
\text { térmicas } \\
\text { (COPEIROS) }\end{array}$ \\
\hline & & & & & $\begin{array}{c}\text { Desinfetar a } \\
\text { esteira } \\
\text { (COPEIROS } \\
\text { e AUX DE } \\
\text { COPA) }\end{array}$ & $\begin{array}{c}\begin{array}{c}\text { Desinfetar o } \\
\text { estoque de } \\
\text { descartáveis } \\
\text { (COPEIROS) }\end{array} \\
\frac{\text { A CADA 15 }}{\underline{\text { DIAS }}}\end{array}$ \\
\hline
\end{tabular}

Higienização com imersão em hipoclorito. ORT = enfermaria ortopedia, OFT = enfermaria oftalmologia, AUX DE COPA = auxiliar de copa. Seguir orientações dos POP's. 


\section{$\checkmark$ Auxiliares de Copa}

\begin{tabular}{|c|c|c|c|c|c|c|}
\hline Segunda-Feira & Terça-Feira & Quarta-Feira & Quinta-Feira & Sexta-Feira & Sábado & Domingo \\
\hline $\begin{array}{c}\text { Higienizar a } \\
\text { máquina de } \\
\text { suco (AUX DE } \\
\text { COPA) }\end{array}$ & $\begin{array}{c}\text { Higienizar a } \\
\text { máquina de } \\
\text { suco (AUX DE } \\
\text { COPA) }\end{array}$ & $\begin{array}{l}\text { Higienizar a } \\
\text { máquina de } \\
\text { suco (AUX } \\
\text { DE COPA) }\end{array}$ & $\begin{array}{c}\text { Higienizar a } \\
\text { máquina de } \\
\text { suco (AUX DE } \\
\text { COPA) }\end{array}$ & $\begin{array}{c}\text { Higienizar a } \\
\text { máquina de } \\
\text { suco (AUX } \\
\text { DE COPA) }\end{array}$ & $\begin{array}{c}\text { Higienizar a } \\
\text { máquina de } \\
\text { suco (AUX DE } \\
\text { COPA) }\end{array}$ & $\begin{array}{c}\text { Higienizar a } \\
\text { máquina de } \\
\text { suco (AUX } \\
\text { DE COPA) }\end{array}$ \\
\hline $\begin{array}{l}\text { Higienizar o } \\
\text { liquidificador* } \\
\text { (AUX DE } \\
\text { COPA) }\end{array}$ & $\begin{array}{l}\text { Higienizar o } \\
\text { liquidificador* } \\
\text { (AUX DE } \\
\text { COPA) }\end{array}$ & $\begin{array}{c}\text { Higienizar o } \\
\text { liquidificador } \\
* \text { (AUX DE } \\
\text { COPA) }\end{array}$ & $\begin{array}{l}\text { Higienizar o } \\
\text { liquidificador* } \\
\text { (AUX DE } \\
\text { COPA) }\end{array}$ & $\begin{array}{c}\text { Higienizar o } \\
\text { liquidificador } \\
* \text { (AUX DE } \\
\text { COPA) }\end{array}$ & $\begin{array}{l}\text { Higienizar o } \\
\text { liquidificador* } \\
\text { (AUX DE } \\
\text { COPA) }\end{array}$ & $\begin{array}{c}\text { Higienizar o } \\
\text { liquidificador } \\
* \text { (AUX DE } \\
\text { COPA) }\end{array}$ \\
\hline $\begin{array}{l}\text { Higienizar os } \\
\text { carros térmicos } \\
\text { (AUX DE } \\
\text { COPA) }\end{array}$ & $\begin{array}{l}\text { Desinfetar os } \\
\text { carros } \\
\text { térmicos } \\
\text { (AUX DE } \\
\text { COPA) }\end{array}$ & $\begin{array}{l}\text { Higienizar os } \\
\text { carros } \\
\text { térmicos } \\
\text { (AUX DE } \\
\text { COPA) }\end{array}$ & $\begin{array}{l}\text { Higienizar os } \\
\text { carros térmicos } \\
\text { (AUX DE } \\
\text { COPA) }\end{array}$ & $\begin{array}{l}\text { Higienizar os } \\
\text { carros } \\
\text { térmicos } \\
\text { (AUX DE } \\
\text { COPA) }\end{array}$ & $\begin{array}{l}\text { Higienizar os } \\
\text { carros térmicos } \\
\text { (AUX DE } \\
\text { COPA) }\end{array}$ & $\begin{array}{l}\text { Higienizar os } \\
\text { carros } \\
\text { térmicos } \\
\text { (AUX DE } \\
\text { COPA) }\end{array}$ \\
\hline $\begin{array}{c}\text { Higienizar a } \\
\text { esteira (AUX } \\
\text { DE COPA) }\end{array}$ & $\begin{array}{c}\text { Higienizar a } \\
\text { esteira (AUX } \\
\text { DE COPA) }\end{array}$ & $\begin{array}{c}\text { Higienizar a } \\
\text { esteira (AUX } \\
\text { DE COPA) }\end{array}$ & $\begin{array}{c}\text { Higienizar a } \\
\text { esteira (AUX } \\
\text { DE COPA) }\end{array}$ & $\begin{array}{c}\text { Higienizar a } \\
\text { esteira (AUX } \\
\text { DE COPA) }\end{array}$ & $\begin{array}{c}\text { Desinfetar a } \\
\text { esteira } \\
\text { (COPEIROS e } \\
\text { AUX DE } \\
\text { COPA) }\end{array}$ & $\begin{array}{c}\text { Higienizar a } \\
\text { esteira (AUX } \\
\text { DE COPA) }\end{array}$ \\
\hline $\begin{array}{c}\text { Desinfetar } \\
\text { utensílios } \\
\text { diversos (AUX } \\
\text { DE COPA) }\end{array}$ & $\begin{array}{c}\text { Higienizar } \\
\text { utensílios } \\
\text { diversos (AUX } \\
\text { DE COPA) }\end{array}$ & $\begin{array}{c}\text { Higienizar } \\
\text { utensílios } \\
\text { diversos } \\
\text { (AUX DE } \\
\text { COPA) } \\
\end{array}$ & $\begin{array}{c}\text { Higienizar } \\
\text { utensílios } \\
\text { diversos (AUX } \\
\text { DE COPA) }\end{array}$ & $\begin{array}{c}\text { Higienizar } \\
\text { utensílios } \\
\text { diversos } \\
\text { (AUX DE } \\
\text { COPA) } \\
\end{array}$ & $\begin{array}{c}\text { Higienizar } \\
\text { utensílios } \\
\text { diversos (AUX } \\
\text { DE COPA) }\end{array}$ & $\begin{array}{l}\text { Higienizar } \\
\text { utensílios } \\
\text { diversos } \\
\text { (AUX DE } \\
\text { COPA) } \\
\end{array}$ \\
\hline \multirow[t]{2}{*}{$\begin{array}{c}\text { Higienizar as } \\
\text { mesas de apoio } \\
\text { (AUX DE } \\
\text { COPA) }\end{array}$} & $\begin{array}{c}\text { Higienizar as } \\
\text { mesas de apoio } \\
\text { (AUX DE } \\
\text { COPA) }\end{array}$ & $\begin{array}{c}\text { Higienizar as } \\
\text { mesas de } \\
\text { apoio (AUX } \\
\text { DE COPA) }\end{array}$ & $\begin{array}{l}\text { Higienizar as } \\
\text { mesas de apoio } \\
\text { (AUX DE } \\
\text { COPA) }\end{array}$ & $\begin{array}{c}\text { Higienizar as } \\
\text { mesas de } \\
\text { apoio (AUX } \\
\text { DE COPA) }\end{array}$ & $\begin{array}{l}\text { Higienizar as } \\
\text { mesas de apoio } \\
\text { (AUX DE } \\
\text { COPA) }\end{array}$ & $\begin{array}{c}\text { Higienizar as } \\
\text { mesas de } \\
\text { apoio (AUX } \\
\text { DE COPA) }\end{array}$ \\
\hline & & & $\begin{array}{l}\text { Desinfetar a } \\
\text { geladeira e } \\
\text { refrigeradores } \\
\text { (AUX DE } \\
\text { COPA) }\end{array}$ & & & 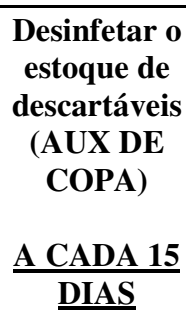 \\
\hline
\end{tabular}

* Realizar a higienização diariamente ou sempre que utilizado. Higienização com imersão em hipoclorito. AUX DE COPA = auxiliar de copa. Seguir orientações dos POP's. 